\title{
Salicornia europaea L. (fam. Chenopodiaceae) Plants as Possible Constituent of Bioregenerative Life Support Systems' Phototrophic Link
}

\author{
Natalia A. Tikhomirovaa, ${ }^{\mathrm{a}, *}$ Sofya A. Ushakova ${ }^{\mathrm{a}}$, \\ Alexander A. Tikhomirova, Galina S. Kalacheva ${ }^{a}$ and Jean-Bernard Gros ${ }^{b}$ \\ ${ }^{a}$ Institute of Biophysics of Siberian Branch of Russian Academy of Sciences, \\ Akademgorodok, Krasnoyarsk, 660036 Russia \\ ${ }^{b}$ LGCB, Universiter B. Pascal, CUST, BP206, 63174 Aubie 're Cedex, Francel
}

Received 2.06.2008, received in revised form 25.08.2008, accepted 27.08.2008

The work is devoted to investigation of productivity, biochemical and mineral composition of Salicornia europaea grown under intensive light culture conditions as applied to bioregenerative life support systems (BLSS). Furthermore influence of amide form of nitrogen on plants growth is investigated in the work. Biochemical composition of the Salicornia europaea edible part showed that raw protein was contained in the highest degree. The water-soluble sugars content and the polysaccharides number (except cellulose) were not high in the Salicornia europaea edible part. It was shown that the plants lipids are characterized by a high unsaturation degree mainly due to alpha linolenic and linoleic acids. Nitrogen nutrition form did not significantly affect the Salicornia europaea productivity. Sodium and its concentrations predominated in the plants mineral composition. Hence Salicornia europaea vegetable plants not only contribute to involvement of sodium chloride in BLSS matter turnover, but also can be the source of several biochemical substances and essential fatty acids for a human.

Keywords: BLSS; mineral nutrition; NaCl matter turnover; Salicornia europaea.

\section{Introduction}

One of the most important problems in perfecting of matter turnover processes in bioregenerative life support systems (BLSS) appears to be creation of technologies providing control and operation of human wastes including $\mathrm{NaCl}$. The halophytes use seems to be one of possible solutions of this problem, in particular the Salicornia europaea plants, capable to accumulate $\mathrm{NaCl}$ in aboveground part in considerable quantity (Balnokin, 2005), at the same time the aboveground part of this plant is fully edible (Ipatiev, 1966).

Our previous works showed that the given plants species utilized sodium chloride in rather high concentrations, used urea as the basic form of nitrogen nutrition and was capable to grow under high concentrations of mineral elements in solutions equivalent to the elements concentrations in the human urine practically without productivity decrease (Tikhomirov, et al., 2005, 2005b; Tikhomirova et al., 2005; Ushakova et al., 2005; Ushakova et al., 2006). However there

\footnotetext{
* Corresponding author E-mail address: ubflab@ibp.ru (C) Siberian Federal University. All rights reserved
} 
is no reference data on biochemical composition of Salicornia europaea and especially on its edible part biochemical composition grown under intensive light culture. The most specific higher plants function in BLSS, which at present cannot be substituted by physicochemical processes, appears to be the biosynthesis of a wide spectrum of nutritive substances necessary for a human. In this connection the object of the given work was investigation of the Salicornia europaea productivity, biochemical and mineral composition when grown under close to BLSS vegetative component conditions (Lisovsky, Shilenko, 1979). As use of human urine after its preliminary physicochemical processing is supposed to be the mineral solution basis for the Salicornia europaea cultivation, it is important to clear up the effect of reduced nitrogen on accumulation of main biochemical matters in Salicornia europaea, necessary for the human diet.

\section{Methods}

Salicornia europaea was grown in artificial conditions in a vegetative, plant growth chamber at the normal ambient $\mathrm{CO}_{2}$ concentration of $-0.034 \%$ (340 ppm). Air temperature was maintained at the level of $24^{\circ} \mathrm{C}$, illumination was continuous. Air relative humidity was $60-70 \%$. The Arc watercooled xenon lamps DKsTV-6000 served as the source of light. Light intensity compounded 690 $\mu \mathrm{mol} /\left(\mathrm{m}^{2} \mathrm{~s}\right)$ of photosynthetically active radiation (PAR).

Procedure of planting stock obtaining is described in our work (Ushakova et al., 2006). Later on the plants were hydroponically grown by the method of water culture in standard stainless steel containers with the nutrient solutions. The modified Tokarev solution (Koval and Shamanin, 1999) containing nitrogen in the form of urea, and the modified Knop solution (Koval and Shamanin, 1999) with nitrate form of nitrogen were used as the nutrient solutions. Modification of the Tokarev solution and the Knop solution was carried out on potassium, concentration of that element in the modified solutions was $168 \mathrm{mg} / \mathrm{l}$ (Knop solution) and $166 \mathrm{mg} / \mathrm{l}$ (Tokarev solution). $\mathrm{NaCl}$ concentration in all variants corresponded to concentration of sodium chloride in the human urine and totaled $10 \mathrm{~g} / \mathrm{l}$. A total of $1.7 \mathrm{mg} / \mathrm{l}$ of trace elements and $2.4 \mathrm{mg} / \mathrm{l}$ of iron citrate were added into the solutions (Koval and Shamanin, 1999). The solutions were aerated with air. Volume of nutrient solutions was maintained at the level of 4.51 per growth container. Six plants were placed in each container and the area of the growth container made up $0.032 \mathrm{~m}^{2}$. The duration of plants vegetation totaled 35 days beginning from the plants replanting under the conditions of continuous growth.

The condition of the plants state was estimated by mass of fresh and dry plants matter, mineral and biochemical plants composition. Plant mineral composition was determined by the following methods: $\mathrm{K}$ and $\mathrm{Na}$ were measured by flame photometry, $\mathrm{Ca}$ and $\mathrm{Mg}$ were recorded by atomic absorption spectroscopy, $\mathrm{N}$ was measured photocolorimetrically by the Kjeldahl method, $\mathrm{P}$ was determined photocolorimetrically, and $\mathrm{S}$ was assessed by titrimetric analysis (Kalacheva et al., 2002). The sodium chloride content was calculated according to the chemical formula.

The methods and conditions of lipids and fatty acids analysis were described in detail in the works (Keits, 1975; Kalacheva et al., 2001). Analysis of methyl ethers of fatty acids was carried out using gas chromatograph with mass spectrometric detecting device (GCD Plus, "Hewlett-Packard", USA).

The content of crude protein in vegetative material was estimated by multiplication of nitrogen quantity on generally accepted for green biomass coefficient 6.25 (Pleshkov, 1976).

Carbohydrates analysis was conducted using the following methods: the carbohydrates' amount 
was determined by hydrolysis with hydrochloric acid and the consequent defining of ordinary sugars by the iodometric method with a copper-alkaline reagent (Pochinok, 1976), the cellulose hydrolysis up to sugars was performed by sulphuric acid with the consequent determination by the iodometric method with a copper-alkaline reagent (Pochinok, 1976).

In the tables and figures the data are represented as arithmetic means of two independent experiments each of them carried out in five biological replication. Biological replication represented measurements carried out on the group of six plants of one container. Difference reliability between two comparative groups was estimated according to the Student's test. The critical value of the Student's coefficient $\left(t_{s t}\right)$ was estimated according to the number of freedom degrees for $95 \%$ level of significance $(\alpha=0,95)$ (Lakin, 1973). The difference of comparative groups was considered to be reliable at $\mathrm{P}<0.05$.

\section{Results and Discussion}

In the result of Salicornia europaea growing in the conditions close to the optimal conditions for plants growth in BLSS "BIOS-3" (Lisovsky, Shilenko, 1979), it was shown that the plants growth did not depend on the form of nitrogen nutrition, and was practically equal in all plants investigated (Table 1). These data once more confirm our previous researches in the result of which it was shown that Salicornia europaea plants could grow on mediums containing nitrogen both in nitrate and amide forms and had practically similar productivity (Tikhomirova et al., 2005; Ushakova et al., 2006).

Analysis of the plants mineral composition showed that nitrogen nutrition forms used did not significantly influence the $\mathrm{Na}$ and $\mathrm{K}$ content in saltwort plants as well as the total nitrogen content in plants roots (Fig.1a, 1b). The nitrogen number was higher in the aboveground plants' organs grown under amide nutrition in comparison with those grown under nitrate nutrition. Very likely this result was concerned with more intense nitrogen absorption by saltwort in amide form in comparison with nitrate nitrogen. Here the saltwort accumulated sodium in the biggest quantity and the amount of this element was in 2.5 times higher in comparison with the potassium quantity. The basic biogenic elements content in the plants of the variants under study was practically identical and considerably lower in comparison with the sodium, potassium and nitrogen contents.

Our data well agree with the halophytes physiological peculiar properties described earlier and demonstrate primary $\mathrm{Na}^{+}$ions accumulation in the aboveground plants organs and the lower $\mathrm{Na}^{+}$ions content in roots owing to sodium ions contained in nutrient solution passed as "transit" to the aboveground organs (Kurkova et al., 1992; Amor et al., 2005).

Biochemical composition analysis of the Salicornia europaea plants grown on solutions with nitrogen in carbamide form showed that both in the plants aboveground organs and the roots there was insignificant and approximately equal amount of water-soluble carbohydrates (Fig.2a, 2b). Total polysaccharides amount

Table 1. Mass of the Salicornia europaea plants grown on nutrient solutions with different forms of nitrogen

\begin{tabular}{|c|c|c|c|c|c|c|c|c|c|c|c|c|}
\hline \multirow{3}{*}{$\begin{array}{l}\text { Variant } \\
\mathrm{NO}_{3}^{-}\end{array}$} & \multicolumn{6}{|c|}{ Mass of aboveground part of one plant, $g$} & \multirow{2}{*}{\multicolumn{3}{|c|}{$\begin{array}{c}\text { Water content of } \\
\text { aboveground part, \% }\end{array}$}} & \multirow{2}{*}{\multicolumn{3}{|c|}{$\begin{array}{l}\text { Dry root weight of } \\
\text { one plant, } g\end{array}$}} \\
\hline & \multicolumn{3}{|c|}{ fresh } & \multicolumn{3}{|c|}{ dry } & & & & & & \\
\hline & 99.4 & \pm & 5.0 & 8.5 & \pm & 0.6 & 91.5 & \pm & 0.3 & 1.2 & \pm & 0.1 \\
\hline $\mathrm{CO}\left(\mathrm{NH}_{2}\right)_{2}$ & 118.9 & \pm & 12.1 & 8.7 & \pm & 0.7 & 92.4 & \pm & 0.4 & 1.3 & \pm & 0.1 \\
\hline
\end{tabular}



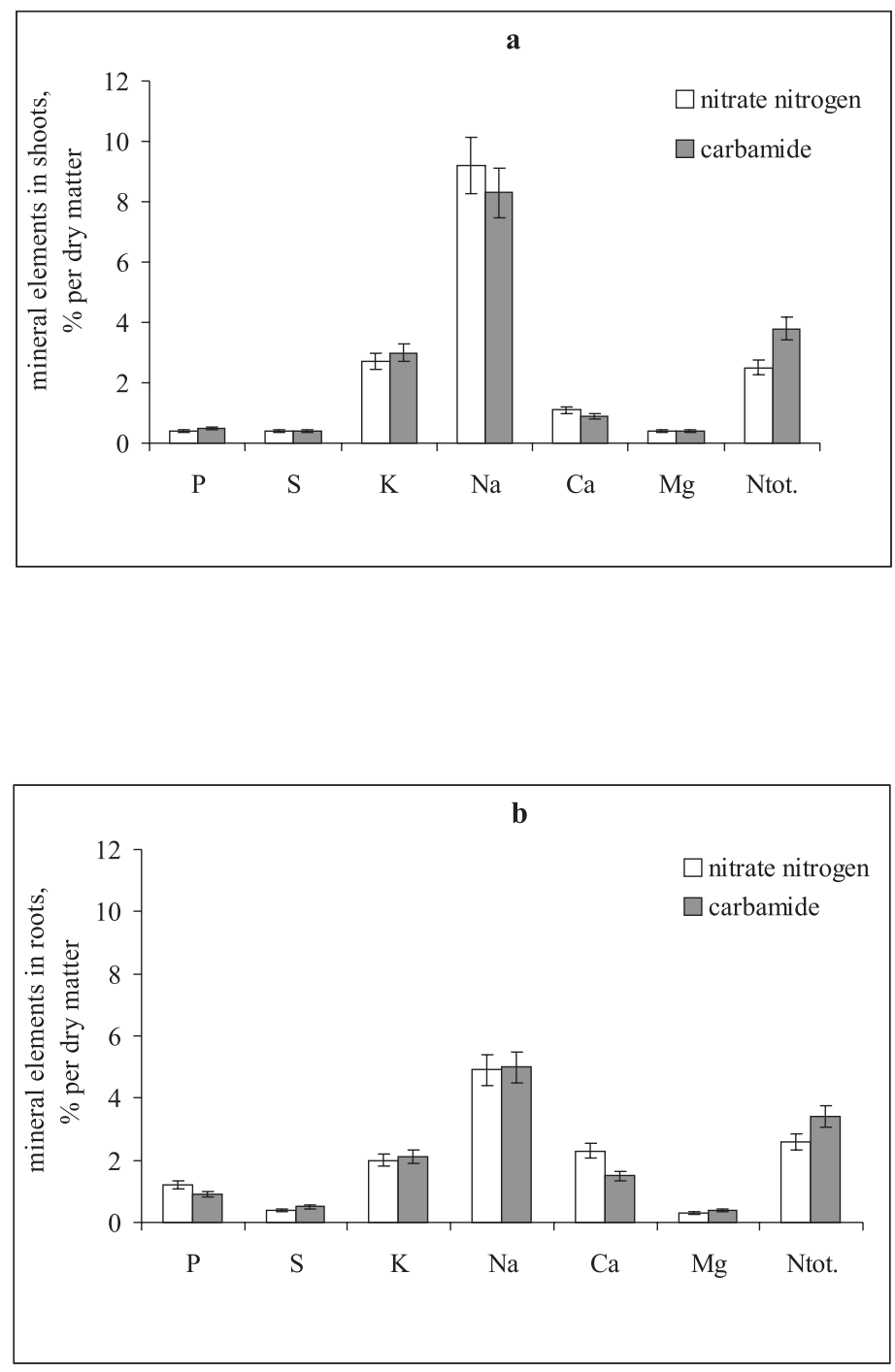

Fig.1. Mineral composition of the Salicornia europaea plants (\% per dry weight) grown on nutrient solutions with different forms of nitrogen: $a$ - mineral composition of plants shoots; $b$ - mineral composition of plants roots

(except cellulose) in plants was more than other carbohydrates quantity. Here in plants roots there were in 2.4 times more compound carbohydrates in comparison with the aboveground organs. Apparently these differences were connected to a bigger amount of hemicellulose in the roots in comparison with the aboveground organs, as far as we visually observed some lignifications of the aboveground plants organs. The relative cellulose amount was also not high, however in the aboveground part in 4.3 times and in the roots in 7.3 times higher than the water-soluble carbohydrates amount.

Crude protein was found in the biggest amount in biochemical composition of the Salicornia europaea plants, the quantity of which appeared to be 21.5-24\% calculating on dry weight. Here there was practically equal amount of this matter both in the aboveground organs and the roots (Fig.2a, 2b).

The lipids content in the aboveground organs was approximately equal to the polysaccharides 

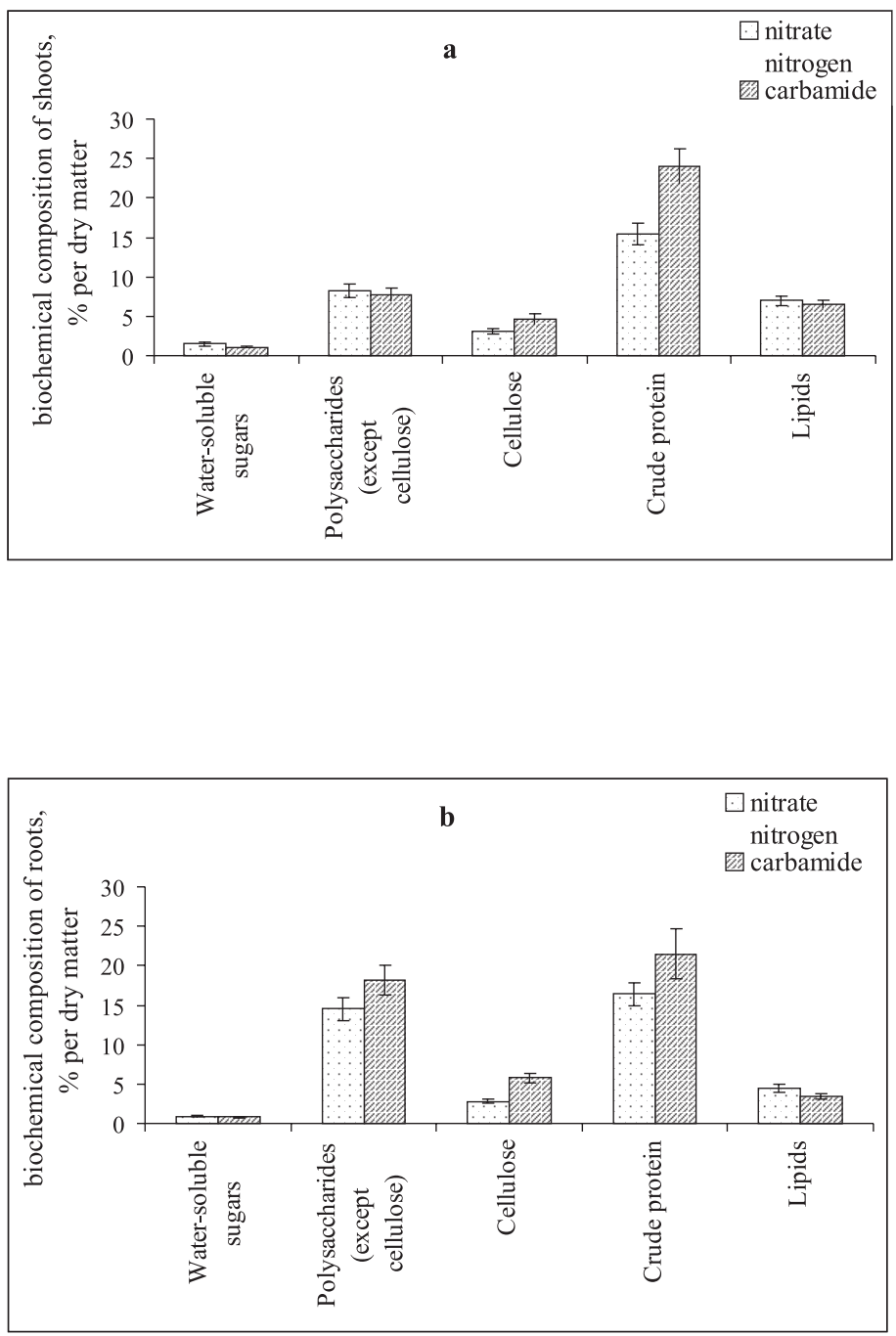

Fig.2. Biochemical composition of the Salicornia europaea plants (\% per dry weight) grown on nutrient solutions with different forms of nitrogen: $\mathrm{a}$ - biochemical composition of plants shoots; $\mathrm{b}$ - biochemical composition of plants roots

content (except cellulose) (Fig.2a). However the lipids content in the roots was on $48 \%$ lower than in the aboveground part (Fig.2a, 2b).

Under plants growing on the solutions with nitrate nitrogen the amount of water-soluble carbohydrates in the aboveground organs and the roots was the same as in the variant with amide nitrogen (Fig.2a, 2b). The nitrogen nutrition form did not affect the total amount of polysaccharides without cellulose in the aboveground plants organs, and the content of these substances in the plants grown under nitrate nutrition was also higher than the other carbohydrates quantity (Fig.2a). In the roots of the plants grown on the solutions with nitrate nitrogen the polysaccharides content without cellulose was on $20 \%$ lower than in the plants grown on amide nitrogen nutrition (Fig.2b). Relative cellulose content was also not high; however the plants grown on solutions with nitrogen in nitrate form contained cellulose in the aboveground part on $34 \%$ and in the roots on 52 

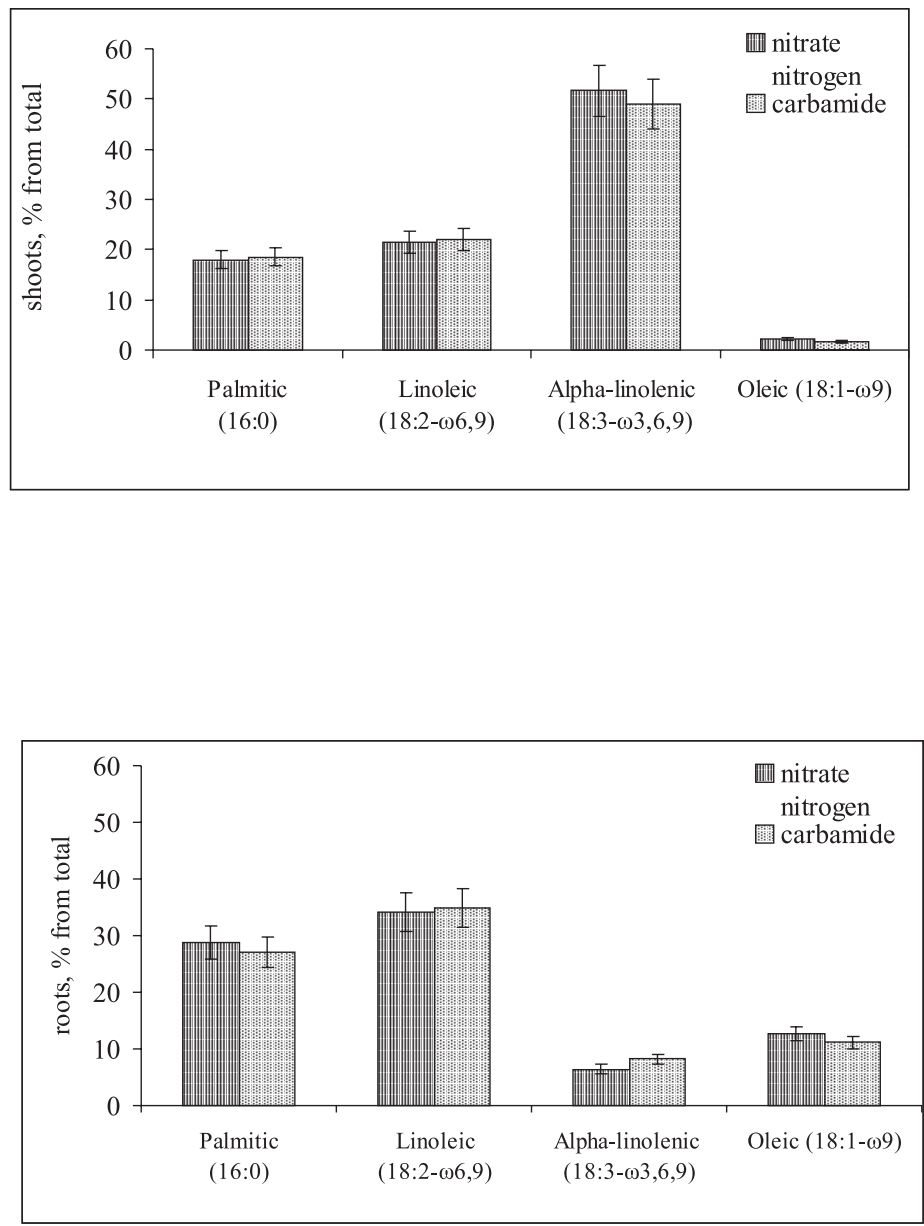

Fig.3. Content of basic fatty acids in Salicornia europaea plants ( $\%$ from total) grown on nutrient solutions with different forms of nitrogen: $\mathrm{a}$ - basic fatty acids in plants shoots; $\mathrm{b}$ - basic fatty acids in plants roots

$\%$ less than the plants grown on the solutions with nitrogen in carbamide form.

Out of dependency on the nitrogen nutrition form the lipid content in the aboveground plants organs was practically identical (Fig.2a). The percentage lipids amount in the plants roots grown on the solutions with nitrate nitrogen was slightly higher than in the variant with amide form of nitrogen (Fig.2b).

In the plants aboveground organs and the roots when grown under nitrate nutrition the content of crude protein was also high, however less on $36 \%$ and $24 \%$ correspondingly in comparison with the plants grown on solutions with carbamide form of nitrogen.

The basic factor of fat quality appears to be fatty-acid composition (Lisovsky, Shilenko, 1979). Analysis of fatty-acid composition showed that the Salicornia europaea plants contained 24 fatty acids, however in fair quantity (more than $5 \%$ from total amount) only 4 fatty acids were present (Fig.3a, 3b). Saltwort fats were characterized by a high degree of unsaturation mainly for the sake of alpha-linolenic and linoleic acids. In the aboveground part of the Salicornia europaea plants about $50 \%$ of alpha-linolenic and $22 \%$ of linoleic acids from the total sum indispensable for 
a human were accumulated (Fig.3a) (Goodwin, Mercer, 1986). Besides the content of palmitic acid typical for the majority of higher plants was considerable and appeared to be about $18 \%$ in the aboveground part and $28 \%$ in the roots from total amount of fatty acids. Oleic acid related to the basic acids of higher plants was found in less quantity.

\section{Conclusion}

The investigation carried out demonstrated that in biochemical composition of the saltwort edible part the crude protein was found in the highest degree. Here the content of crude protein and cellulose in plants grown on solutions with amide nitrogen was higher than in plants grown on solutions with nitrate nitrogen. The form of nitrogen nutrition did not considerably influence the content of other biochemical substances in saltwort plants. In spite of the lipids content in saltwort plants was relatively low it was shown that the plants fats were characterized by a high degree of unsaturation mainly, owing to alpha- linolenic and linoleic acids. Our investigations showed that according to nutritive value the edible biomass of the Salicornia europaea plants grown on the solutions with urea addition was highly competitive with the plants biomass grown on nitrate nutrition.

The forms of nitrogen nutrition under study did not influence the Salicornia europaea productivity, and from the area of $0.032 \mathrm{~m}^{2}$ it was gathered from $51 \mathrm{~g}$ (nitrate nutrition) to $51.6 \mathrm{~g}$ (amide nutrition) of edible dry biomass. Here in edible plants biomass depending on nitrogen form accumulated from $10.7 \mathrm{~g}$ (amide nutrition) to 11.7 $\mathrm{g}$ (nitrate nutrition) $\mathrm{NaCl}$ on $0.032 \mathrm{~m}^{2}$.

Thus being vegetables Salicornia europaea plants can serve as the source of several biochemical substances and fatty acids indispensable for a human. Here the nitrogen source can be compounds containing it both in nitrate and reduced forms. That considerably simplifies the technologies choice of the Salicornia europaea growing under its inclusion in the BLSS higher plants unit.

\section{Acknowledgements}

The work was conducted under support of INTAS grant \# 05-1000008-8010 and the project \# 5.16 of SB RAS.

\section{References}

Amor N.B., Hamed K.B., Debez A., Grignon C., Abdelly Ch. (2005) Physiological and antioxidant responses of the perennial halophyte Chrithmum maritimum to salinity. Plant Sci. 168: 889-899.

Balnokin Yu. V. (2005) Rasteniya v usloviyah stressa (Plants in stress conditions) In: Yermakov I.P. (ed.) Phiziologiya rastenii (Plant physiology). Academy, Moscow, p. 510-587 (in Russian).

Goodwin T.W., Mercer E.I. (1986) Vvedenie v biochimiyu rastenii (Introduction to plant biochemistry), vol. 1. Mir, Moscow, 393 p. (in Russian).

Ipatiev A.N. (1966) Ovoshchnyye Rasteniya Zemnogo Shara (Vegetable plants of the Earth), Vysheishaya shkola, Minsk, Byelorussia, 384 p. (in Russian).

Kalacheva G.S., Gubanov V.G., Gribovskaya I.V., Gladchenko I.A., Zinenko G.K., Savitsky S.V. (2002) Chemical Analysis of Lake Shira Water (1997-2000). Aquatic Ecology 36: 123-141.

Kalacheva G.S., Zhila N.O., Volova T.G. (2001) The Botryococcus green algae's lipids in the course of phasic development in a periodic cell culture. Microbiology 70: 305-312. (in Russian). 
Keits M. (1975) Tekhnika lipidologii. Vydelenie, analyz i identifikatsiya lipidov (Technique of lipidology. Lipids' isolation, analysis and identification). Mir, Moscow, 305 p. (in Russian).

Koval S.F., Shamanin V.P. (1999) Rastenie v opyte (Plant in experiment). OmSAU, Omsk, 204 p. (in Russian).

Kurkova Ye.B., Balnokin Yu.V., Myasoyedov N.A. (1992) Some properties of cells ultra structure and $\mathrm{Na}^{+}$and $\mathrm{Cl}^{-}$accumulation in the Petrosimonia triandra halophytes' tissues. Fiziologiya Rastenii (Russian Journal of Plant Physiology) 39: 32-39.

Lakin G.F. (1973) Biometriya (Biometry). Vysshaya shkola, Moscow, 344 p. (in Russian).

Lisovsky G.M., Shilenko M.P. (1979) Vybor strukturyi i usloviy funktsionirovaniya zvena "vysshiye resteniya" (Choice of a structure and functioning conditions of the "higher plants" link). In: Lisovsky G.M. (ed.), Zamknutaya sistema chelovek-vysshiye rasteniya (Humans-higher plants closed system). Nauka, Novosibirsk, 160 p. (in Russian).

Pleshkov B.P. (1976) Praktikum po biokhimii rastenii (Practical work on plant biochemistry). Kolos, Moscow, 256 p. (in Russian).

Pochinok Kh.N. (1976) Metody biochimicheskogo analyza rasteniy (Methods of plants' biochemical analysis). Naukova Dumka, Kiyev, 334 p. (in Russian).

Tikhomirov A.A., Ushakova S.A., Kudenko Yu.A., Kovaleva N.P., Zolotukhin I.G., Tikhomirova N.A., Velichko V.V., Gros J.B., Lasseur Ch.. (2005a) Evaluation of the possibility of using human and plant wastes in bioregenerative life support systems. Technical paper 2005-01-2981, SAE International.

Tikhomirov A.A., Ushakova S.A., Kovaleva N.P., Kudenko Yu.A., Zolotukhin I.G., Tikhomirova N.A., Velichko V.V. (2005b) Some ways of waste utilization for a bioregenerative life support system. In: Proceedings of the International Symposium on Closed Habitation Experiments and Material Circulation Technology. Japan, p. 210-213.

Tikhomirova N.A., Ushakova S.A., Kovaleva N.P., Gribovskaya I.V., Tikhomirov A.A. (2005) Influence of high concentrations of mineral salts on production process and $\mathrm{NaCl}$ accumulation by Salicornia europaea plants as a constituent of the LSS phototroph link. Adv. Space Res. 35: 15891593.

Ushakova S.A., Kovaleva N.P., Gribovskaya I.V., Dolgushev V.A.and Tikhomirova N.A. (2005) Effect of $\mathrm{NaCl}$ concentration on productivity and mineral composition of Salicornia europaea as a potential crop for utilization $\mathrm{NaCl}$ in LSS. Adv. Space Res. 36: 1349-1353.

Ushakova S.A., Kovaleva N.P., Tikhomirova N.A., Gribovskaya I.V., Kolmakova A.A. (2006) Effect of photosynthetically active radiation, salinization, and type of nitrogen nutrition on growth of Salicornia europaea plants. Russian Journal of Plant Physiology 53: 886-894. 